\title{
Attitudes toward Contraception Initiation in the Emergency Department among Providers and Patients
}

Nathan VanderVinne, DO ${ }^{1}$, Sydney Ryckman, BS ${ }^{1}$, Lynn Coy, DO ${ }^{1}$, Kimberly Swartz, MD JD ${ }^{1}$, Caitlin Bernard, MD ${ }^{1}$, Jeffrey Kline, MD ${ }^{1}$

${ }^{1}$ Indiana University School of Medicine, Department of Emergency Medicine

\section{Background and Hypothesis:}

In $2011,45 \%$ of 6.1 million pregnancies were unintended. Women between the ages of 20-24, those with lower education, lower income, and of African American descent had higher rates of unintended pregnancies. In 2014, there were 25.9 million visits to the ED by women under the age of 24 .i Intervention within the Emergency Department to assess fertility status and provide contraception when appropriate has the potential to help reduce the number of mistimed and unwanted pregnancies.

\section{Experimental Design or Project Methods:}

This study aims to assess the attitudes toward providing contraception within the Emergency Department via surveys. The provider survey will be sent through a large national list serve; the patient survey was given to women 18-45 years old within the Emergency Departments of a large county hospital and inner-city urban hospital.

\section{Results:}

So far, 200 surveys were collected. 32 women were planning to get pregnant within the next year, 135 were not attempting to get pregnant, 13 were unsure, and 20 could not get pregnant. The number of women who were unsure or did not want to get pregnant totaled to 148 ; out of these women, $62 \%$ showed interest in receiving access to birth control within the ED. We still plan to do more data analysis, including how many of these women are currently using birth control and demographic analysis looking at race, education level, and relationship status.

\section{Conclusion and Potential Impact:}

If there is substantial interest, we will then conduct a study to initiate contraception within the ED. This will hopefully contribute to reducing the unintended pregnancy rate.

\footnotetext{
' Finer, L. B. and M. R. Zolna (2016). "Declines in Unintended Pregnancy in the United States, 2008-2011." N Engl J Med 374(9): 843-852.

ii https://www.cdc.gov/nchs/data/nhamcs/web_tables/2014_ed_web_tables.pdf
} 